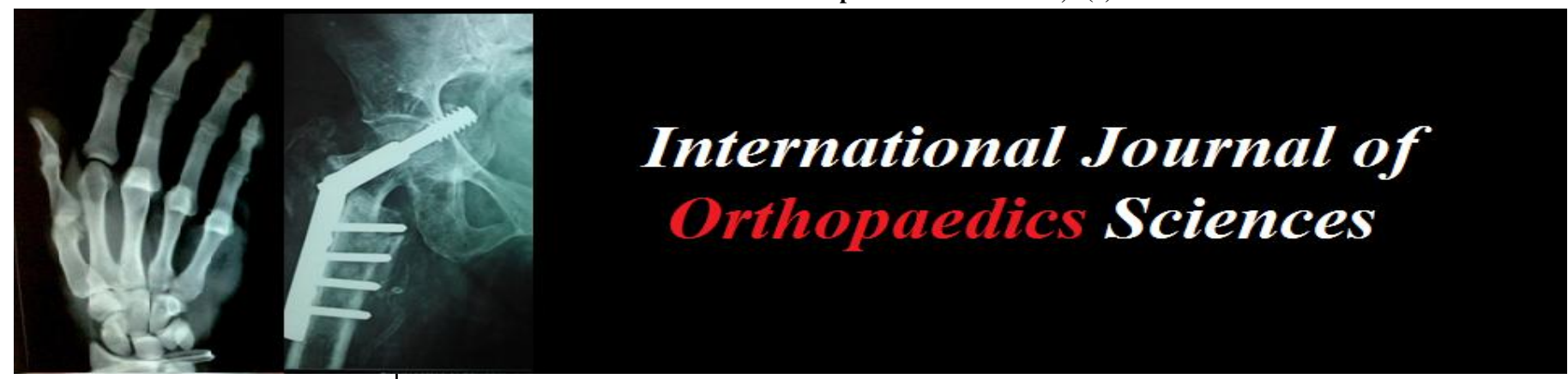

ISSN: $2395-1958$

IJOS $2019 ; 5(2): 216-218$

(C) 2019 IJOS

www.orthopaper.com

Received: 03-02-2019

Accepted: 05-03-2019

Dr. Muhamed Wasil NP

A.J Institute of Medical Science

\& Research Centre, Mangalore,

Karnataka, India

Dr. Sudeep Shetty

A.J Institute of Medical Sciences

\& Research Centre, Mangalore,

Karnataka, India

Dr. Mithun Shetty

A.J Institute of Medical Science

\& Research Centre, Mangalore,

Karnataka, India
Correspondence

Dr. Muhamed Wasil NP

A.J Institute of Medical Science

\& Research Centre, Mangalore,

Karnataka, India

\section{A case of medial tibial plateau split depressed fracture treated with ORIF \& plating with bone substitute}

\author{
Dr. Muhamed Wasil NP, Dr. Sudeep Shetty and Dr. Mithun Shetty
}

DOI: https://doi.org/10.22271/ortho.2019.v5.i2e.22

\section{Abstract}

Tibial plateau fractures are complex intraarticular fractures that usually have a variety of fracture patterns $\&$ associated ligament injury. Concomitant ligament injury is one of the major problem \& is easily missed because of the nature of fracture configuration.

This is a case report of a patient with medial tibial plateau split depressed fracture who underwent ORIF \& Plating with Bone Substitute.

Keywords: Tibial plateau fracture, ORIF (open reduction\& internal fixation), bone substitute

\section{Introduction}

Medial tibial plateau split depressed fracture is a rare fracture pattern with small number of case reports in the literature. Isolated medial tibial plateau split depressed fracture is not explained in any of the classification. These were predominantly treated nonoperatively till 1970s with traction, cast bracing \& even spica casting. 1980s onwards, improved methods of ORIF became with an advantage of reducing the articular surface, alligning the limb \& mobilizing the knee early. Recently hydroxyapatite crystals containing various forms of calcium are started using instead of autograft because the former prevents the collapse \&helps in new bone formation.

To our knowledge this is the first study of a patient with medial plateau split depressed fracture with isolated PCL that couldn't be explained by mode of injury. Patient was treated by ORIF \& plating with bone substitute \& was evaluated preop, 6,12 \& 24 weeks postoperatively.

Radiographic union was assessed by plain X-Ray \& CT scan.

\section{Case Report}

A 31 years old Male presented with a history of slip \& fall at home following sustained injury to left knee. Patient was taken to local hospital where he was diagnosed to have proximal tibia fracture after X-ray \& Above knee slab was given. He was referred to our hospital for further management.

Patient had pain \& swelling of left knee following the incident, on examination there was localised swelling, tenderness, warmth over the left knee with restricted range of motion. Special tests couldn't assess due to the severe pain \& instability. There was no neurovascular deficit.

Patient is evaluated with X ray \& CT scan of left knee which confirmed left medial tibial plateau depressed fracture. Case was operated through the medial approach. Fracture window was opened by incising MCL in line with fracture. Depressed fragment was elevated under fluoroscopy guiedance \& bone substitute was applied for preventing further collapse. Anatomic reduction achieved through the plates \& the subchondral area is stabilized \& articular surface is maintained through 2 parallel screws under fluoroscopy guiedance. Patient was immobilized postoperatively for 6 weeks \& range of motion exercises along with quadriceps \& hamstring strengthening exercises. Partial weight bearing started at 6 weeks \& Full weight bearing initiated at 3 months.

He came to hospital with a complaint of instability to left knee for which he was diagnosed to 
have isolated PCL injury clinically (Posterior drawer test +) which is treated conservatively by physiotherapy. He was improved after 3 months of physiotherapy in view of instability \& range of motion of the left knee. There was good radiological union at the end of 6 months

\section{Discussion}

Fractures of the tibial plateau involves the articular surface of the proximal tibia, it represents $1 \%$ of fractures in adults in which medial tibial plateau split depression fractures are $<5 \%$. CT scan is mandatory as it demonstrates articular depression, displacement \& comminution more clearly than plain radiograph. More advanced $3 \mathrm{D}$ reconstruction images will give spatial relationship of the fracture fragments. Several studies proved that long term problem will be residual laxity due to bony depression rather than ligament laxity. Synthetic crystals (Hydroxyl apatite crystals with tricalcium phosphate) are recent advance in surgery for minimising this problem which reduce the subsidence after fixation \& prevent secondary displacement.

Bajammal et al. found that all patients whom are treated with fixation with bone substitute had good radiological \& clinical outcome according to Rasmussen's score. Bucholz et al. found that all all patients achieved preoperative level of activity after surgery \& there was no significant difference between the pre \& post-operative Tegner score.

Calcium phosphate is an injectable, moldable \& biocompatible bone substitute that has been used as a synthetic bone void filler. Augmenting with Calcium phosphate was shown to fill the bone defect \& prevent collapse of the fracture site. In addition to mechanical strength they are gradually reabsorbed over time \& replaced by host bone. However the rate of Calcium phosphate resorption should be balanced with rate of new bone formation to prevent fragment subsidence. This is a case report of a patient with medial tibial plateau split depressed fracture who underwent Orif \& Plating with Bone Substitute.

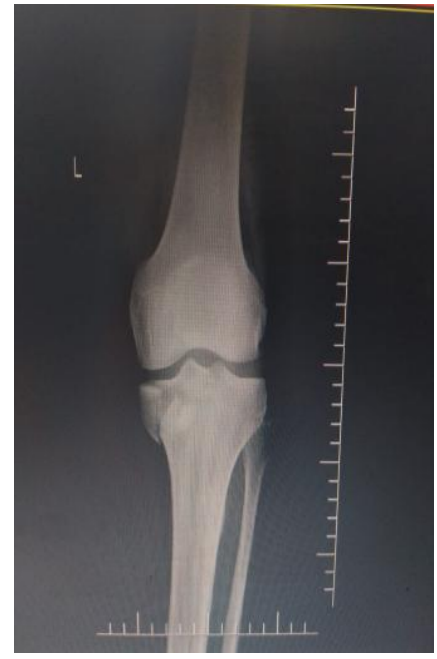

Preop

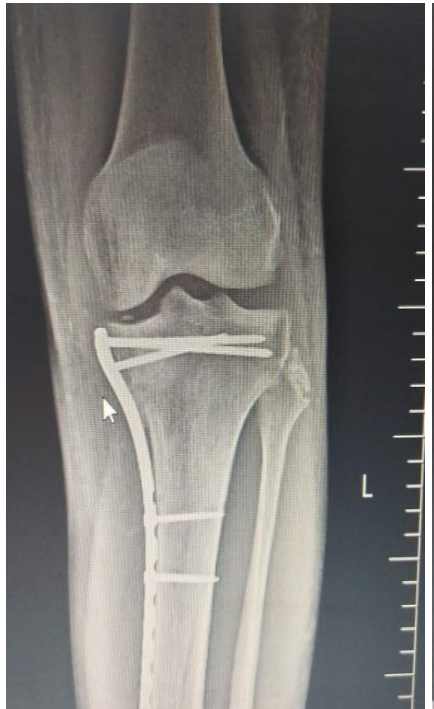

12 Weeks

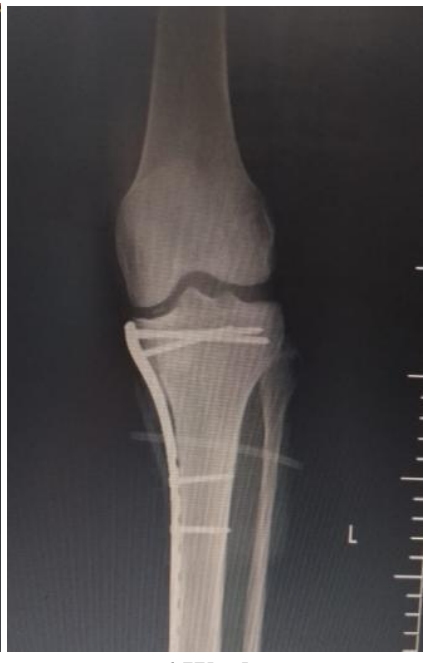

6 Weeks

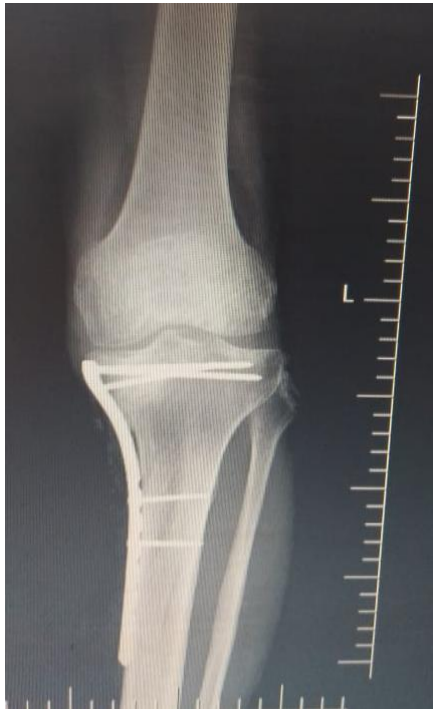

24 Weeks

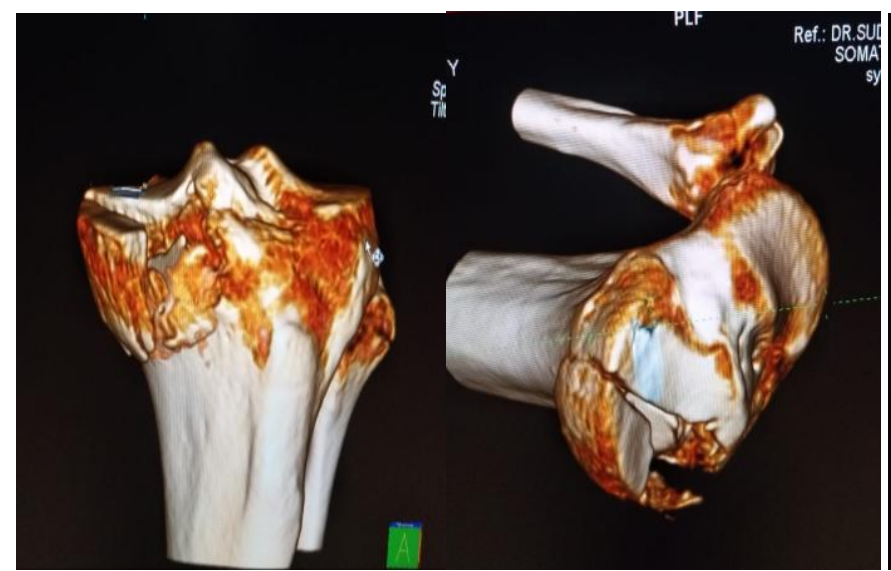

Preop

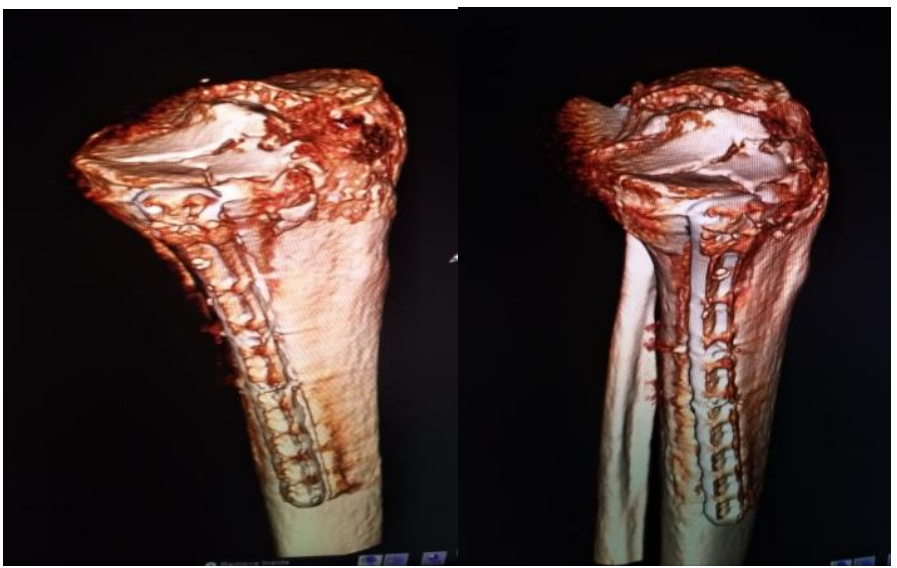

Post OP

\section{Conclusion}

The most important consideration of tibial plateau fractures are the restoration of plateau surface by anatomic reduction, for that subchondral defects must be filled to prevent joint surface from subsiding when the bone is subjected to loading. Synthetic hydroxy apatite crystal with TCP is a better bone substitute that can be used as a synthetic bone void filler.

Medial condyle split depression fractures are unique \& it might present with isolated PCL injury which needs careful evaluation with CT \& MRI scans.

Articular reduction of the depressed fragment has to be done

$\&$ maintenance of this rigid fixation should be done with bone graft / substitute to achieve favourable outcome.

\section{References}

1. Bajammal SS, Zlowodzki M, Lelwica A et al. The use of calcium phosphate bone cement in fracture treatment. J Bone Joint Surg. Am. 2008; 90(6):1186-1196.

2. Bucholz RW, Carlton A, Holmes R. Interporous hydroxyapatite as a bone graft substitute in tibial plateau fractures. Clin Orthop Relat Res. 1989; (240):53-62.

3. Musahl V, Tarkin I, Kobbe P, Tzioupis C, Siska PA, 
Pape HC. New trends and techniques in open reduction and internal fixation of fractures of the tibial plateau. $\mathbf{J}$ Bone Joint Surg Br. 2009; 91:426-33.

4. Egol KA, Koval KJ. Fractures of the proximal tibia. In: Bucholz RW, Heckman JD, Court-Brown C, editors. Fracture in adults. 6th ed. Philadelphia: Lippincott; 2006; 2:1999-2029.

5. Whittle AP, Wood GW. Fractures of lower extremity. In: Canale ST, editor. Campbell's operative orthopaedics. 10th ed. Philadelphia: Mosby. 2003; 3:2725-872.

6. Segur JM, Torner P, García S, Combalía A, Suso S, Ramón R. Use of bone allograft in tibial plateau fractures. Arch Orthop Trauma Surg. 1998; 117:357-9.

7. Duwellius PJ, Rangitsch MR, Colville MR, Woll TS. Treatment of tibial plateau fractures by limited internal fixation. Clin Orthop Relat Res. 1997; (339):47-57.

8. Lasanianos N, Mouzopoulos G, Garnavos C. The use of freeze-dried cancellous allograft in the management of impacted tibial plateau fractures. Injury. 2008; 39:110612.

9. Bansal MR, Bhagat SB, Shukla DD. Bovine cancellous xenograft in the treatment of tibial plateau fractures in elderly patients. Int Orthop. 2009; 33:779-84.

10. Goulet JA, Senunas LE, De-Silva GL, Greenfield ML. Autogenous iliac crest bone graft. Complications and functional assessment. Clin Orthop Relat Res. 1997; (339):76-81.

11. fiimflek A, Çakmak G, Cila E. Bone grafts and the materials that can be used for bone grafts. [Article in Turkish] TOTB $<$ D Dergisi. 2004; 3:79-90.

12. Yetkinler DN, Mc-Clellan RT, Reindel ES, Carter D, Poser RD. Biomechanical comparision of conventional open reduction and internal fixation versus calcium phosphate cement fixation of a central depressed tibial plateau fracture. J Orthop Trauma. 2001; 15:197-206.

13. Trenholm A, Landry S, Mc-Laughlin K, Deluzio KJ, Leighton J, Trask K et al. Comparative fixation of tibial plateau fracture using alpha-BSM, a calcium phosphate cement, versus cancellous bone graft. J Orthop Trauma. 2005; 19:698-702.

14. Welch R, Zhang H, Bronson DG. Experimental tibialplateau fractures augmented with calcium phosphate cement or autologous bone graft. J Bone Joint Surg Am. 2003; 85-A:222-31.

15. Wheeler DL, Cross AR, Eschbach EJ, Rose AT, Gallogly PM, Lewis DD et al. Grafting of massive tibial subchondral bone defects in a caprine model using betatricalcium phosphate versus autograft. J Orthop Trauma. 2005; 19:85-91.

16. Russell TA, Leighton RK, Alpha-BSM. Tibial Plateau Fracture Study Group. Comparison of autogenous bone graft and endothermic calcium phosphate cement for defect augmentation in tibial plateau fractures. A multicenter, prospective, randomized study. J Bone Joint Surg Am 2008; 90:2057-61.

17. Manzotti A, Confalonieri N, Pullen C. Grafting of tibialbone defects in knee replacement using Norian skeletal repair system. Arch Orthop Trauma Surg. 2006; 126:594-8.

18. Simpson D, Keating JF. Outcome of tibial plateau fractures managed with calcium phosphate cement. Injury. 2004; 35:913-8.

19. Keating JF, Hajducka CL, Harper J. Minimal internal fixation and calcium-phosphate cement in the treatment of fractures of the tibial plateau. A pilot study. J Bone
Joint Surg Br. 2003; 85:68-73.

20. Schildhauer TA, Bauer TW, Josten C, Muhr G. Openreduction and augmentation of internal fixation with an injectable skeletal cement for the treatment of complex calcaneal fractures. J Orthop Trauma 2000; 14:309-17.

21. Kelly CM, Wilkins RM, Gitelis S, Hartjen C, Watson JT, Kim PT. The use of a surgical grade calcium sulfate as a bone graft substitute: results of a multicenter trial. Clin Orthop Relat Res. 2001; (382):42-50.

22. Larsson S, Bauer TW. Use of injectable calcium phosphate cement for fracture fixation: a review. Clin Orthop Relat Res. 2002; (395):23-32.

23. Walsh WR, Morberg P, Yu Y, Yang JL, Haggard W, Sheath PC et al. Response of a calcium sulfate bone graft substitute in a confined cancellous defect. Clin Orthop Relat Res. 2003; (406):228-36. 